\title{
Comunicação, recepção e consumo: suas inter-relações em Rebelde-RBD 1
}

Fernanda Elouise Budag

Professora colaboradora da disciplina Estudos de Recepção, na Escola Superior de Propaganda e Marketing (ESPM-SP). Mestra em Comunicação e Práticas de Consumo pela ESPM-SP. Graduada em Comunicação Social - Publicidade e Propaganda, pela Universidade Regional de Blumenau - FURB.

E-mail: fernanda_eb@yahoo.com.br

Resumo: Nosso objeto de estudo são as inter-relações recepção/consumo na telenovela Rebelde e banda RBD. Destacamos as questões relacionadas à produção de sentidos que, de acordo com nossas análises, por mais que promovam a polissemia, situam-se de maneira próxima à mensagem hegemônica veiculada. TrabaIhamos também as práticas de consumo que permeiam a recepção deste mesmo produto midiático e identificamos que a importância tão marcante do consumo material ante o consumo simbólico está no que chamamos de materialização da lembrança.

Palavras-chave: recepção, consumo, telenovela, identidade, jovens.
Abstract: Our study object is the interrelations reception/consumption in the Rebelde soap opera and RBD teenage band. We emphasize issues related to the production of meanings that, according to our analysis, in despite of promoting polissemy, are situated so close to the hegemonic message conveyed. We also upon the practices of consumption that permeate the reception of that media product and we identified that the importance so striking of the material consumption front of the symbolical one is situated in what we call materialization of memory.

Keywords: reception, consumption, soap opera, identity, teenagers.

Qual o momento exato em que começamos a decidir nossa vida? Quem testou nossos pais pra saber se seriam capazes de escolher o melhor pra gente? Quando eles escolhem nosso colégio, será que têm a consciência de que esse lugar vai marcar nossa história pra sempre? ${ }^{2}$

Este é o discurso inicial da telenovela Rebelde $e^{3}$ E, igualmente a ele, podemos dizer que nosso discurso inicial também terminava em ponto de interrogação, ou melhor, interrogações - no plural: o que há nesta telenovela que atrai tanto os jovens? Recursos, valores, temáticas etc. O que vêem os jovens neste produto midiático? Por que o consomem? Quais os sentidos produzidos?

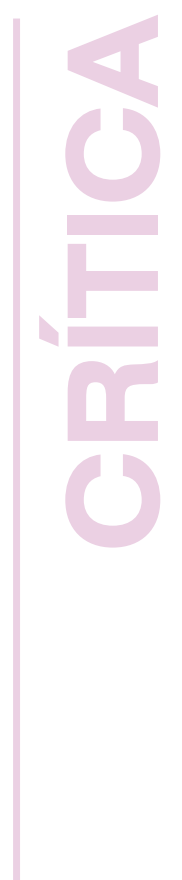

Recebido: 13/6/2008

Aprovado: $16 / 6 / 2008$

1. Artigo produzido a partir da dissertação apresentada ao programa de Mestrado em Comunicação e Práticas de Consumo (ESPM-SP), sob orientação da Profa. Dra. Maria Aparecida Baccega.

2. REBELDE - primeira temporada da novela. Direção: Juan Carlos Muñoz e Luis Prado. Produção: Pedro Damián. Interpretação: RBD e outros. Roteiro original: Patricia Maldonado. México: Televisa, Videolar, 2006. 3 DVDs (780 min.), son., color. (00:01:35 - 00:01:54).

3. REBELDE - primeira temporada da novela. Direção: Juan Carlos Muñoz e Luis Prado. Produção: Pedro Damián. Interpretação: RBD e outros. Roteiro original: Patricia Maldonado. México: Televisa, Videolar, 2006. 3 DVD (780 min.), son., color. REBELDE - segunda temporada da novela. Direção: Juan Carlos Muñoz e Luis Prado. Produção: 
Pedro Damián. Interpretação: RBD e outros. Roteiro original: Patricia Maldonado. México: Televisa Videolar, 2006. 3 DVD (780 min.), son., color. REBELDE - terceira temporada da novela. Direção: Juan Carlos Muñoz e Luis Prado. Produção: Pedro Damián. Interpretação: RBD e outros. Roteiro original: Patricia Maldonado. México: Televisa, Videolar, 2007. 3 DVD (780 min.), son., color.

4. OROZCO GÓMEZ, Guillermo. La telenove la en Mexico: ¿de una expresión cultural a un simple producto para la mercadotecnia? Comunicación y Sociedad, Guadalajara, n. 6, p. 30, jul./dez. 2006.

5. Ibid., p. 17.

6. Fazemos referência aqui aos seguintes dados: o último capítulo de $\operatorname{Re}$ belde foi ao ar, no Brasil, no dia 29 de dezembro de 2006, e a banda RBD realizou, um ano e quatro meses depois (nos dias 10 e 11 de maio de 2008), três shows em São Paulo com ingressos esgotados.

7. A esse respeito ver: CARRASCOZA, João Anzanello; FURTADO, Juliana de Assis. Rebelde: estratégia mercadológica de rizoma e tática discursiva de árvore. Comunicação e Educação, São Paulo: CCA-ECA-USP/Paulinas, Ano XII, n. 3, set./dez. 2007.
Não construímos hipóteses propriamente ditas como ponto de partida. Porém, tínhamos algumas pistas para orientar, principalmente, nossos primeiros passos. A primeira delas é a constatação de que Rebelde foi concebida desde o princípio para vender mercadorias e, entre elas, sobretudo a banda $R B D$. Dialogamos então com Orozco Gómez ${ }^{4}$, segundo o qual, a partir dos anos 2000, as telenovelas mexicanas entraram em uma quinta etapa de seu desenvolvimento industrial, chamada por ele de mercantilización. As telenovelas hoje são produzidas para ser vendidas. E é deste pressuposto que partimos para fazer nossas reflexões. O próprio autor cita Rebelde, explicando que hoje a tendência de produção de uma telenovela é reduzir-se o melodrama e aumentar os efeitos espetaculares com a intenção de chamar a atenção do telespectador e estimular o consumo.

¡La telenovela y quienes la realizan hoy en día parecen estar simplemente preocupados por venderla! Para ello [os produtores das telenovelas] junto con la telenovela se despliega toda una "estrategia de marketing". Y esta estrategia, independentemente del reconocimiento por parte de la audiencia, busca solamente su aceptación. La telenovela, entonces, muestra imágenes atractivas, como las de sus actores semidesnudos masculinos y femeninos, y muestra rasgos de moda, tanto en el vestido como en el lenguaje y los gestos, que al presentarse con caras y cuerpos atractivos se hacen apetecibles a los ojos de los televidentes, y por tanto consumibles ${ }^{5}$.

E aqui se insere a segunda pista com a qual começamos a estudar este produto cultural midiático: RBD (a banda) deu origem a Rebelde (a telenovela), e não o oposto, como pode ter deixado transparecer a mídia e pode ter sido entendido pelo público em geral. A nosso ver, no formato de um produto rentável (obviamente, porque o objetivo de todo produto midiático é gerar audiência e conseqüente venda de espaços publicitários), a telenovela mostrou-se, aos seus produtores, uma ótima propaganda para divulgar a banda que, por sua vez, fazendo sucesso, teria uma vida mais longa do que sua matriz. No Brasil, as produções têm uma duração média de seis a oito meses; já uma banda possui, intrínseca à sua natureza, a possibilidade de uma vida mais longa. Da mesma forma, trabalhando com temáticas universais - que interessam à média dos jovens em países representativos no globo terrestre -, uma banda seria bemsucedida no mundo todo. Tudo isto, com efeito, aconteceu: Rebelde foi assistida em mais de 70 países e $R B D$, por exemplo, ainda arrebata jovens brasileiros mesmo quase um ano e meio após o término da telenovela ${ }^{6}$. É um fato ainda mais interessante quando levamos em consideração a efemeridade típica desse tipo de produto midiático.

Interessamo-nos, pois, em buscar pistas para tentar descortinar as relações comunicação/consumo agenciadas por Rebelde-RBD. Mais especificamente, procuramos estudar as produções de sentido que emergem no processo de recepção de Rebelde e as singularidades nas práticas de consumo geradas a partir deste mesmo processo ${ }^{7}$. 


\section{RESSIGNIFICAÇÃO DE REBELDIA}

Como o próprio nome da telenovela em questão sugere, reconhecemos a rebeldia como um dos principais valores que permeiam toda a trama de Rebelde. Dessa forma, queremos trabalhar aqui as produções de sentido que giram em torno dessa temática.

A polissemia - "[...] deslocamento, ruptura de processos de significação"8 -, a diferença de acepções que os receptores dão às mensagens recebidas da mídia, mostra-se presente quando analisamos os enunciados que nossos entrevistados deram à questão: Para você, o que significa ser rebelde? Há a emergência de uma série de sentidos.

Os integrantes do nível socioeconômico $A$, ao responderem a este questionamento, dividem-se claramente em dois grupos: os que vinculam a palavra rebelde a independente e os que a associam a extrovertido. Fornecem-nos definições do tipo: ser rebelde é ser livre (ter liberdade); poder fazer o que quiser na hora que quiser; ser independente e ter atitude; ser uma pessoa travessa; ser legal e ser tudo e ser descolado.

Já nos discursos dos jovens de nível socioeconômico $B$, a maior ocorrência é da definição bastante generalista de rebelde como ser legal. Em verdade, legal é uma palavra de significado tão aberto que deixa de ter valor para a compreensão do que foi dito. E começamos a encontrar, neste nível socioeconômico, jovens que não responderam ou disseram não saber responder a questão proposta. Também encontramos as categorias independente e extrovertido que apareceram nos discursos dos jovens de nível socioeconômico A: ser rebelde é ser uma pessoa firme e forte; significa caráter e bom senso; ter muita atitude e ser independente; ser extrovertido e divertido.

No nível socioeconômico $C$ ocorre uma divergência de discurso em relação aos dois níveis imediatamente superiores. Aparece um sentido mais negativo de rebelde, com expressões como: ser rebelde é ser desobediente; ser uma criança malcriada e respondona; quando não segue as regras, é muito impaciente; significa jovens bagunceiros; significa desobedecer aos pais, mal educado e ignorante; ser mal educado e que não fica respeitando os mais velhos e significa ser muito respondona, agitada. Percebemos nesses enunciados, que chamamos de negativos, a presença de valores conservados pela cultura que, em geral, não são seguidos - apenas ditos - pela geração que os divulga. São tradicionais. A rigor, esse rebelde que emerge no discurso dos integrantes de nível socioeconômico $\mathrm{C}$ é aquele que se revolta somente contra a microestrutura - no ambiente de sua casa ou no ambiente da escola, por exemplo - e não se interessa pela esfera social mais ampla.

Vemos, então, um mesmo produto cultural midiático - Rebelde - sendo recebido, lido e interpretado de maneiras diferentes, possibilitando a geração de uma rede de sentidos, estes às vezes distintos. Enfim, as definições de ser rebelde derivam de diversos sítios de significaça a ${ }^{9}$, produzindo novos conceitos para o termo. Com isto, ressaltamos, desde já, uma importante constatação de nosso estudo. No processo de recepção de Rebelde, as ressignificações operadas pelos

8. ORLANDI, Eni Puccinelli. Análise de discurso: princípios e procedimentos. 7. ed. Campinas, SP: Pontes, 2007. p. 36.

9. Ibid., p. 39. 
comunicação \& educação • Ano XIII • Número 3 • set/dez 2008

10. RONSINI, Veneza Mayora. Mídia, cultura e classe: a ordem da diferença. 16ㅇ Encontro Anual da Associação Nacional dos Programas de Pós-Graduação em Comunicação, 2007, Curitiba. Anais do 16을 Encontro Anual da Associação Nacional dos Programas de Pós-Graduação em Comunicação. Curitiba Compós, 2007. p. 14-15.

11. REBELDE - terceira temporada da novela. Direção: Juan Carlos Muñoz e Luis Prado. Produção: Pedro Damián. Interpretação: RBD e outros. Roteiro original: Patricia Maldonado. México: Televisa Videolar, 2007. 3 DVDs (780 min.), son., color. (01:24:43 - 01:25:34). receptores fazem emergir novas conceituações de rebeldia que nos parecem fundamentais destacar. Seus receptores esvaziam o significado de rebeldia em dois sentidos. Primeiro, porque afirmam que rebelde é ser legal, expressão que exprime um grande número de atributos positivos e acaba por ser muito generalista, retirando a carga de revolta que o adjetivo rebelde possui. Segundo, porque a rebeldia, que até então remetia a uma tentativa de ação de mudança da macroestrutura e a uma ida de encontro à autoridade constituída na busca de uma modificação profunda dos valores da sociedade, passa a ser, conforme os receptores de Rebelde, uma revolta que se esgota na microestrutura - no âmbito da escola e da família. Restringe-se simplesmente à já conhecida crise da adolescência: o jovem briga com os pais por causa de alguma questão insignificante e não questiona, por exemplo, a instituição familiar. Em suma, a telenovela Rebelde ressignifica a noção de rebelde.

Consideramos que um caminho adequado para pensarmos sobre essa postura de agir microssocialmente passa pelo que diz Ronsini: "No final das contas, o desejo de liberdade, a ousadia e o inconformismo se resumem ao poder de comprar um estilo 'próprio' e os significados que caracterizam a juventude contemporânea acabam por estar em comunhão com a economia capitalista"10.

De certa maneira, Ronsini consegue resumir bem a articulação entre consumo e identidades agenciada por uma telenovela cujo título remete à transgressão, mas que, inserida na cultura midiática, parece esvaziar-se de sentidos concretamente transformadores.

\section{PREDOMINÂNCIA DA LEITURA HEGEMÔNICA}

Até aqui, vimos emergir as acepções de rebeldia presentes nos discursos dos jovens receptores de Rebelde. Mas cabe um questionamento: como essa mesma rebeldia é trabalhada no discurso da telenovela? Vejamos um enunciado representativo dessa temática, pronunciado pelo Professor Madariaga, personagem da trama:

[Vocês, alunos] mostraram uma união, como grupo, incrível. Me surpreenderam. E mais uma vez enfrentaram tudo para defender a um de vocês. A uma de vocês, nesse caso. [...] O melhor de tudo... O melhor de tudo, gente, é que por trás dessa rebeldia de vocês, mostraram ter valores muito fortes. Muito fortes. Eu sei que no dia de amanhã essa força vai fazer com que possam mudar muitas coisas. E ainda que cresçam (acreditem, vai acontecer), não percam isso, gente! De verdade. Não percam essa rebeldia, mas sempre com razão e com o coração ${ }^{11}$.

O Professor Madariaga está inserido no núcleo central da telenovela. É um personagem do bem que está presente no início de Rebelde, depois fica ausente da trama e retorna ao final. É muito querido pelos alunos e, assim, consideramos um personagem muito importante. Em verdade, ele aparece como um ponto positivo da telenovela, pois - não somente nessa situação, mas em muitas outras - fala coisas dirigidas a uma situação de mudança de fato, conforme o trecho já citado ("essa força vai fazer com que possam mudar muitas coisas"). 
Não fica claro qual é essa mudança a que o personagem se refere, se é macro ou microssocial, mas trata-se de uma alteração das coisas de maneira geral. E mais: ressalta o uso da razão e do coração, que pensamos ser uma mensagem importante.

Porém, ao mesmo tempo, notamos que o Professor Madariaga nem precisava ter feito uso da palavra rebeldia ("por trás dessa rebeldia de vocês"). Percebemos então que rebeldia, em Rebelde, é utilizada como substituta da palavra atitude, por exemplo. Portanto, a telenovela defende que é preciso que os jovens tenham uma postura pró-ativa. O que é bom. Contudo, analisando esta cena conjuntamente com as demais desse tipo em Rebelde, compreendemos que a telenovela acaba sustentando uma rebeldia com causas que se restringem à esfera escolar ou à pessoal desses personagens - não se aprofunda na macroestrutura social. Geralmente, conforme apontam as histórias no transcorrer da telenovela, as causas da rebeldia - de nível micro - são injustiças que ocorrem com um ou outro colega. Na situação citada, a injustiça era a expulsão de uma aluna grávida.

Como apresentamos há pouco, os receptores apropriam-se exatamente desta mesma noção de rebelde como ator social que atua de maneira restrita e por causas de importância mínima para o sistema social em sua totalidade. Parece-nos, pois, que há uma predominância da leitura hegemônica das mensagens midiáticas por parte desses jovens. Podemos inferir que a recepção de Rebelde se dá tão proximamente porque a telenovela de fato consegue trabalhar com o que está presente nos anseios de jovens de todo o mundo. São questões superficiais, originárias de um repertório estreito e construído sem reflexões de nível macro. Um exemplo seria a temática da corrupção que Rebelde aborda. Ao final da trama, presenciamos um filho denunciando seu pai, um político corrupto. Aliás, este gesto é altamente discutível, porque lembra a situação do estado nazista em que os jovens eram motivados a denunciar seus pais. Não vamos adentrar nesta questão, mas o que queremos destacar é que a rebeldia se concentra apenas aí, na corrupção, que é uma palavra de ordem da classe média. Denunciar a corrupção não significa trazer mudanças consideráveis ao sistema capitalista, como, por exemplo, a distribuição mais igualitária da renda ou a melhoria das condições de vida da população. Mais uma vez, a rebeldia aparece concentrada em um ponto localizado, sem extrapolá-lo. Na realidade, é abordada pelos produtores de Rebelde com foco na superficialidade típica dos jovens.

\section{SINGULARIDADES NAS PRÁTICAS DE CONSUMO DE REBELDE-RBD}

O consumo é questão fulcral em nosso estudo, pois estamos investigando as práticas de consumo efetuadas por jovens receptores de Rebelde-RBD. Há um interesse pelo modo como os bens materiais são utilizados e valorados pelo consumidor, que é concebido como agente ativo. 
2. SILVERSTONE, Roger. Por que estudar a mídia? 2. ed. São Paulo: Edições Loyola, 2005. p. 150

13. ROCHA, Everardo. Culpa e prazer: imagens do consumo na cultura de massa. Comunicação, mídia e consumo, São Paulo, v. 2, n. 3, p. 123-138, mar. 2005; aqui, p. 135.

14. HAMBURGER, Esther. O Brasil antenado: a sociedade da novela. Rio de Janeiro: Jorge Zahar, 2005. p. 54.
Segundo Silverstone, "[...] o consumo é a única atividade essencial pela qual nos envolvemos, diariamente, com a cultura de nossos tempos"12. Pois, de fato, "coisas como moda, objetos, produtos, serviços, design, marcas, grifes, shoppings, televisão, publicidade, comunicação de massa são traços indeléveis no espirito do tempo [da sociedade contemporânea], e cada um à sua maneira dá ampla visibilidade ao consumo na nossa vida social cotidiana"13.

Notamos em nossa pesquisa de campo que o consumo perpassa todos os níveis socioeconômicos. No entanto, foi nítido perceber (ver figura a seguir) como a quantidade de produtos cresce à medida que descemos na escala de níveis socioeconômicos. No nível socioeconômico A, obtivemos uma média de 1,3 produto comprados por consumidor; no nível socioeconômico B, 2,2 e, no nível socioeconômico $\mathrm{C}, 2,5$. Ou seja, o oposto da condição econômica. Dialogamos, então, com Hamburger, que afirma que o nível socioeconômico C seria o segmento mais essencial para as emissoras de TV no Brasil porque, “[...] embora possua menos recursos para gastar, seus membros representariam uma porção maior da população brasileira, além de supostamente consumirem mais que membros das classes $\mathrm{B}{ }^{14}$.

FIGURA 1 - Gráfico com categorias de produtos por nível socioeconômico

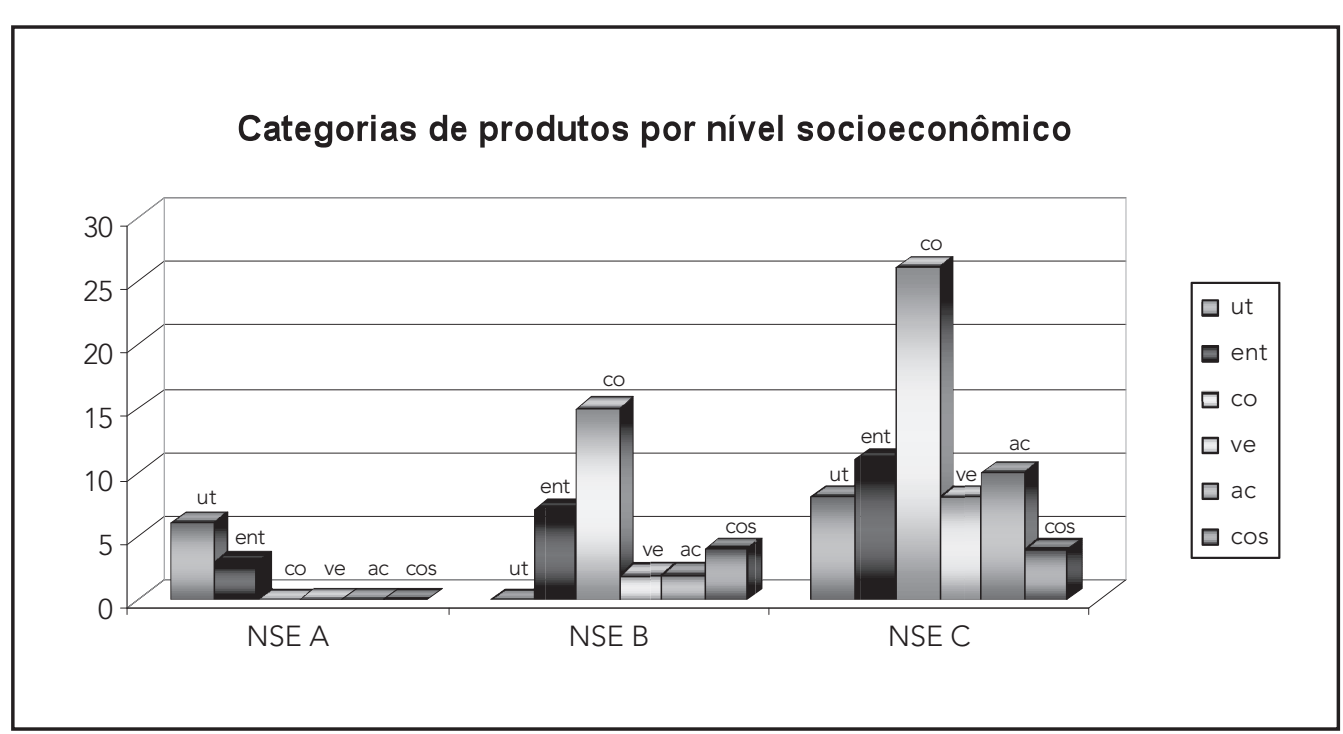

ut $=$ utilidade $/$ ent $=$ entretenimento $/ \mathrm{co}=$ colecionáveis $/$ vê $=$ vestimenta $/ \mathrm{ac}=$ acessórios $/ \mathrm{cos}=$ cosmético (Fonte: Pesquisa realizada pela autora com receptores de Rebelde, na cidade de São Paulo.)

Damos continuidade às questões concernentes à relação do consumo com a telenovela. Para tanto, empreendemos um breve deslocamento para dar conta do que queremos dizer: no lugar da telenovela, voltamos no tempo e trazemos o seu antecessor, o folhetim. No romance Madame Bovary, de Gustave Flaubert, o autor apresenta uma personagem - Emma Bovary - da qual, entre suas várias características, destacamos o seu apetite pela leitura de folhetins e romances e seu impulso pelo consumo, na França do século XIX. E aqui citamos Costa: "Emma é uma consumidora implacável de bens imaginários. 
Para ela, 'comprar e ler constituem manifestações da mesma síndrome, porque a leitura romântica estimula o consumo e o comprar se transforma num prolongamento do deleite de ler"'. ${ }^{15}$ De certa forma, é uma personagem à frente de seu tempo. Nossa contemporânea. Podemos transpor esta situação para o contexto atual, e, substituindo o ato de ler pelo ato de assistir à televisão (telenovela), no caso específico de Rebelde, o consumo compõe a fruição da telenovela.

Parodiando Costa, afirmamos que assistir à telenovela estimula o consumo e este se transforma em um prolongamento da assistência à telenovela. Não apenas a temática do amor romântico, que distraía e comprazia Emma Bovary, mas várias outras temáticas presentes em Rebelde incentivam experiências, desejos e sensações que levam ao consumo.

Vale a pena salientarmos resultados sobre a valorização, a importância que estes jovens imputam ao fato de possuírem produtos de Rebelde-RBD. A grande maioria dos entrevistados respondeu que é muito importante ter esses produtos da banda e da telenovela: alguns ficaram no discurso superficial, dizendo apenas que é importante porque gostam dos seus ídolos. Mas outros deram algumas pistas para pensarmos além. As maiores ocorrências são de jovens que declararam achar importante ter os produtos de Rebelde-RBD para guardar como recordação. Num primeiro momento é até espantosa a consciência que muitos deles mostraram possuir de que a banda acabará um dia, demonstrando como a lógica mercadológica do showbizz é perfeitamente conhecida por eles. Alguns discursos mais representativos desta categoria são:

(1) "acho que sim [é importante ter os produtos]. Porque é uma recordação. Porque eu sei que um dia vai acabar. A novela já acabou. Um dia a banda vai acabar. Aí vai ser a recordação de tudo isso. De uma fase boa";

(2) "sim [é importante ter os produtos], se eu gosto deles. Assim, tipo, acho que é uma forma de demonstrar meu carinho por eles também. Tendo sempre guardado. Porque, tipo, ter sempre guardado uma lembrança deles vai ser sempre bom. Porque não sei se vai durar pra sempre. Então, vai ter sempre guardado alguma coisa";

(3) "ah, [é importante ter os produtos] pra quando você crescer, você se lembrar que você gostou daquele grupo e tal. Quando sentir saudade lá, ficar abraçando lá. Aí eu gosto";

(4) "pra mim é importante [ter os produtos] porque eu posso, todo dia que me dá vontade, ir lá, poder ler, poder ver de novo. Tudo o que eu passei. Os momentos que tava... Pra mim, foi feliz, entendeu. Sempre recordar".

Enfim, os jovens têm vontade de comprar os produtos vinculados a Rebelde e $R B D$ como uma forma de materialização da lembrança: uma vez que eles possuem consciência de que a banda não é eterna - a telenovela já chegou ao fim, por exemplo -, eles querem comprar os produtos para guardar como recordação de um momento bom de suas vidas.
15. COSTA, Cristiane. Eu compro essa mulher: romance e consumo nas telenovelas brasileiras e mexicanas. Rio de Janeiro: Jorge Zahar, 2000 p. 40. 
comunicação \& educação • Ano XIII • Número 3 • set/dez 2008

\section{BREVES CONSIDERAÇÕES}

No que diz respeito ao processo de recepção de Rebelde-RBD, por mais que tenhamos encontrado situações nas quais os jovens receptores revelam sua atividade - na construção de múltiplas significações para o conteúdo recebido -, percebemos a predominância de pontos de vista sedimentados, hegemônicos.

Já no que concerne às práticas de consumo, notamos ao menos um dos porquês da supervalorização, por parte dos jovens, do consumo material de bens vinculados ao produto midiático do qual são receptores. De certa forma, adotam um comportamento que concorda com a lógica de mercado na qual estão inseridos: ante a efemeridade dos produtos simbólico-midiáticos, resta a alternativa da compra para materializá-los, na tentativa de torná-los mais perenes.

Longe da pretensão de esgotarmos o tema e de apresentarmos nossas constatações como conclusivas ou únicas possíveis, cremos ter conseguido lançar luz sobre o que nos interessava nas relações comunicação/consumo ou, particularmente, telenovela/consumo.

\section{REFERÊNCIAS BIBLIOGRÁFICAS}

CARRASCOZA, João Anzanello; FURTADO, Juliana de Assis. Rebelde: estratégia mercadológica de rizoma e tática discursiva de árvore. Comunicação e Educação, São Paulo: CCA-ECA-USP/Paulinas, Ano XII, n. 3, set./dez. 2007.

COSTA, Cristiane. Eu compro essa mulher: romance e consumo nas telenovelas brasileiras e mexicanas. Rio de Janeiro: Jorge Zahar, 2000.

HAMBURGER, Esther. O Brasil antenado: a sociedade da novela. Rio de Janeiro: Jorge Zahar, 2005.

ORLANDI, Eni Puccinelli. Análise de discurso: princípios e procedimentos. 7. ed. Campinas, SP: Pontes, 2007.

OROZCO GÓMEZ, Guillermo. La telenovela en Mexico: ¿de una expresión cultural a un simple producto para la mercadotecnia? Comunicación y Sociedad, Guadalajara, n. 6, p. 11-35, jul./dez. 2006.

ROCHA, Everardo. Culpa e prazer: imagens do consumo na cultura de massa. Comunicação, mídia e consumo, São Paulo, v. 2, n. 3, p. 123-138, mar. 2005.

RONSINI, Veneza Mayora. Mídia, cultura e classe: a ordem da diferença. 16 ${ }^{\circ}$ Encontro Anual da Associação Nacional dos Programas de Pós-Graduação em Comunicação, 2007, Curitiba. Anais do 16º Encontro Anual da Associação Nacional dos Programas de Pós-Graduação em Comunicação. Curitiba: Compós, 2007.

SILVERSTONE, Roger. Por que estudar a mídia? 2. ed. São Paulo: Edições Loyola, 2005. 